\title{
Variações anatômicas no aparelho reprodutor masculino de Chaunus ornatus (Wied-Neuwied, 1821) (Anura, Bufonidae)
}

\author{
Classius de Oliveira ${ }^{1,3}$, Lia Raquel de Souza Santos ${ }^{2}$ \& Rodrigo Zieri ${ }^{2}$
}

Biota Neotropica v7 (n1)-http://www.biotaneotropica.org.br/v7n1/pt/abstract?article+bn01207012007

\author{
Recebido em 13/07/06 \\ Versão reformulada recebida em 10/12/06 \\ Publicado em 10/01/07
}

\author{
${ }^{1}$ Universidade Estadual Paulista - UNESP, Campus de São José do Rio Preto, \\ Instituto de Biociências Letras e Ciências Exatas, Departamento de Biologia, \\ Rua Cristóvão Colombo, 2265, Jardim Nazareth, CEP 15054000 São José do Rio Preto, SP, Brasil \\ ${ }^{2}$ Programa de Pós-graduação em Biologia Animal, IBILCE - UNESP/SJRP \\ ${ }^{3}$ Autor para correspondência: Classius de Oliveira, e-mail: classius@ibilce.unesp.br,www.ibilce.unesp.br
}

\begin{abstract}
Oliveira, C., Santos, L.R.S. \& Zieri, R. Anatomical variations in the male reproductive system of Chaunus ornatus (Wied-Neuwied, 1821) (Anura, Bufonidae). Biota Neotrop. Jan/Apr 2007 vol. 7, no. 1 http:// www.biotaneotropica.org.br/v7n1/pt/abstract?article+bn01207012007 ISSN 1676-0603.

This work describes morphologic variations in the organs and structures of the male reproductive system in Chaunus ornatus, analyzed independently from the alterations that promote structural variations. Seven adult samples were used, they were collected in Botucatu (São Paulo State, Brazil) during reproductive activity period. The specimens were dissected and rostrum-cloacal length measures were taken. Descriptive and biometrics anatomical analyses were also obtained. Three of these animals were sent to histological routine for the analysis of the testicular architecture, where it was schematized in vegetable paper with pen Indian ink. Statistical analyses (mean, standart deviation, Shapiro-Wilk test, Student's t and Simple Lineal Regression) were used for interpretation of the results. The testes of $C$. ornatus are cylindrical with white coloration and they possess a rudimentary ovarian structure, the Bidder's organ, in the testicular cranial extremity. The male reproductive system of $C$. ornatus presents conspicuous anatomical variations intra and interindividuals, especially to the form and size of the testes and of the Bidder's organ, which did not present relationship with the size of individual. As for the location, the testes are disposed ventral to the kidneys, but they are in different levels, accompanying differences attributed to the kidneys levels. The disposition and number of extensions in the abdominal fatty bodies is variable among the pair's members, and consequently among individuals. Histologically differences regarding the germ epithelium arrangement were not observed. The germ epithelium is arranged in seminiferous locule, therefore these characteristics seem to follow the pattern of the description for the other anurans. The morphologic heterogeneity for anatomical variations in that species were few significant. Thus, other studies are still necessary for the establishment of morphologic relations and its phylogenetic implications, as well as to understand how the evolutionary pressures act modeling this anuran structures anatomy.
\end{abstract}

Keywords: amphibia, testis, Bidder's organ, fatty bodies.

\section{Resumo}

Oliveira, C., Santos, L.R.S. \& Zieri, R. Variações anatômicas no aparelho reprodutor masculino de Chaunus ornatus (Wied-Neuwied, 1821) (Anura, Bufonidae). Biota Neotrop. Jan/Apr 2007 vol. 7, no. 1 http:// www.biotaneotropica.org.br/v7n1/pt/abstract?article+bn01207012007 ISSN 1676-0603.

Este trabalho descreve variações morfológicas nos órgãos e estruturas do aparelho reprodutor masculino em Chaunus ornatus, analisados independentemente das alterações promotoras de variações estruturais. Foram utilizados sete exemplares adultos da espécie, coletados no Município de Botucatu (São Paulo, Brazil) na época de atividade reprodutiva. Os espécimes foram dissecados e medidas do comprimento rostro-cloacal, análises anatômicas descritivas e biométricas foram obtidas. Três destes animais foram encaminhados à rotina histológica para a análise da arquitetura testicular e esquematizada em papel vegetal com caneta nanquim. Análises estatísticas (média, desvio-padrão, teste de Shapiro-Wilk, teste t de Student e Regressão Linear Simples) foram empregadas para interpretação dos resultados. Os testículos de C. ornatus são cilíndricos com coloração branco-leitosa e possuem uma estrutura ovariana rudimentar, o órgão de Bidder, em sintopia com a extremidade testicular cranial. O aparelho reprodutor masculino de C. ornatus apresenta conspícuas variações anatômicas intra e interindividuais, especialmente no que concerne à forma e tamanho dos testículos e dos órgãos de Bidder, os quais não apresentaram relação com o tamanho do indivíduo. Quanto à localização, os testículos dispõem-se ventralmente aos rins, mas ocorrem em alturas diferentes, acompanhando diferenças atribuídas à própria posição dos rins. Nos corpos adiposos abdominais, a disposição e número de prolongamentos que o constitui é variável entre os membros do par, e conseqüientemente entre indivíduos. Histologicamente não foram observadas diferenças quanto ao arranjo do 
epitélio germinativo na constituição do lóculo seminífero, portanto estas características parecem seguir o padrão da descrição para os demais anuros. A heterogeneidade morfológica quanto às variações anatômicas nessa espécie teve uma constatação pouco significativa. Assim, outros estudos ainda são necessários para o estabelecimento de relações morfológicas e suas implicações filogenéticas, bem como para compreender como as pressões evolutivas atuam moldando a anatomia dessas estruturas nos anuros.

Palavras-chave: anfíbio, testículo, órgão de Bidder, corpos adiposos.

\section{Introdução}

Para as três ordens viventes de anfíbios, são constituintes do aparelho reprodutor, testículos e ovários conectados por meio de ductos genitais próprios constituindo a via gametogênica, representada pelos dúctulos eferentes e ducto de Wolff nos machos e pelos ovidutos ou ducto de Müller nas fêmeas. Após a diferenciação e o desenvolvimento sexual do indivíduo, freqüentemente também são descritas estruturas vestigiais que permanecem como não funcionais. Para a família Bufonidae, o órgão de Bidder ocorre em macho e em fêmeas (Witschi 1933, Wake 1980, Pancak-Roessler et al. 1990, Duellman \& Trueb 1994, Farias et al. 2002, Oliveira et al. 2003a) e é exclusivo para esse táxon.

Nos anuros os testículos são descritos como órgãos pares, arredondados, compactos, de cor geralmente amarelada, esbranquiçada ou branco-leitosa. Podem apresentar variações anatômicas de forma e peso de acordo com o período reprodutivo (Duellman \& Trueb 1994), além de outras alterações morfofuncionais associadas à reprodução (Lofts 1974), como descrito para algumas espécies (Montero \& Pisanó 1990, 1992, Lampo \& Medialdea 1996, Huang et al. 1997, Oliveira \& Vicentini 1998). Quanto à arquitetura morfológica, os testículos são revestidos pela túnica albugínea, que confina o parênquima testicular constituído por tecido germinativo arranjado em lóculos seminíferos delimitados por tecido conjuntivo frouxo (Oliveira \& Vicentini 1998, Oliveira et al. 2002, Oliveira et al. 2003a, Oliveira \& Zieri, 2005).

$\mathrm{Na}$ família Bufonidae, há relevantes contribuições sobre o órgão de Bidder, morfologia testicular e espermatogênese: Chaunus arenarun (Cavicchia \& Moviglia 1982); C. ornatus (Oliveira et al. 2003a). C. icterictus (Farias et al. 2002); C. marinus (Lampo \& Medialdea 1996); Duttaphrynus melanostictus (Huang et al. 1997); Amietophrynus regularis (Abdelmaguid \& Sabry 1987); Anaxyrus woodhousii (Atherton 1974); Nectophrynoides malcolmi (Wake 1980); N. occidentalis (Zuber-Vogeli \& Xavier 1966) e genus Telmatobius (Montero \& Pisanó 1990).

Pelo fato de existirem poucos trabalhos sobre a anatomia dos órgãos e estruturas do aparelho reprodutor masculino dos anuros, especialmente nos animais de regiões neotropicais, o propósito foi descrever algumas variações morfológicas nos órgãos desse aparelho, mas analisados independentemente de alterações estruturais decorrentes da reprodução. Em Chaunus ornatus (Wied-Neuwied 1821), pertencente à família Bufonidae, cujos representantes manifestam aspectos anatômicos típicos, procurou-se interpretar as variações anatômicas do aparelho reprodutor e apresentar uma caracterização morfológica geral dos testículos, órgão de Bidder e dos corpos adiposos abdominais.

\section{Material e Métodos}

Foram utilizados sete exemplares adultos da espécie Chaunus ornatus, coletados no Município de Botucatu (São Paulo, Brasil $-22^{\circ} 59^{\prime} \mathrm{S}$ and $48^{\circ} 25^{\prime} \mathrm{W}$ ), na época de atividade reprodutiva, quando os indivíduos são facilmente encontrados no hábitat natural. Os exemplares estão depositados na Coleção Herpetológica do Departamento de Zoologia e Botânica do IBILCE (nº 06013 a 06018). $\mathrm{O}$ estudo limitou-se a estabelecer a variabilidade anatômica dos ór- gãos do aparelho reprodutor masculino sem considerar as alterações morfológicas decorrentes da ciclicidade da reprodução, a qual é acompanhada por muitas mudanças nesses órgãos. Por essa razão o estudo compreendeu um número relativamente limitado de indivíduos que foram analisados no intervalo de um curto período no intuito de minimizar as influências de fatores externos sob os animais.

Os espécimes, previamente fixados, foram dissecados e a partir dos sete indivíduos foram obtidas medidas do comprimento padrão rostro-cloacal e análises anatômicas macroscópicas descritivas e biométricas. Três destes animais foram destinados aos estudos microscópicos.

Após a redução do testículo a pequenos fragmentos, o material foi devidamente lavado e em seguida fixado por 24 horas em solução de karnovisky (paraformaldeído 4\% e glutaraldeído $2 \%$ em tampão fosfato Sorensen $0,1 \mathrm{M}, \mathrm{pH}$ 7,3). Em seguida foi encaminhado à rotina histológica (Ribeiro \& Lima 2000) para inclusão em resina do tipo methacrilato glicol (Historesin Leica ${ }^{\circledR}$ ). Cortes de $2 \mu \mathrm{m}$ foram corados com Hematoxilina/Eosina e destinados à análise histológica. A organização morfológica testicular foi examinada em microscópio óptico Olympus BX 60, acoplado com sistema de câmara clara, a partir do qual foram elaborados esquemas em papel vegetal com caneta nanquim.

A análise estatística constituiu-se da obtenção e análise das médias e desvio-padrão. Verificou-se a existência de valores discrepantes e a normalização dos dados pelo teste de Shapiro-Wilk. A dependência entre as gônadas foi obtida com o teste t de Student e a correlação dos dados gonadais com as demais mensurações pelo teste de Regressão Linear Simples. Para os testes foi utilizado nível de significância de $5 \%$.

\section{Resultados e Discussão}

O aparelho reprodutor masculino de Chaunus ornatus apresenta conspícuas variações anatômicas intra e interindividuais, especialmente no que concerne à forma e tamanho dos testículos e dos órgãos de Bidder. A variação dos corpos adiposos abdominais foi diagnosticada, mas tem menor expressão. De modo a simplificar, a partir da análise de cada indivíduo, são apresentadas inicialmente as variações anatômicas intra-individuais comparando-se as diferenças entre os antímeros e em seguida os exemplares foram comparados quanto às variações anatômicas interindividuais.

As variações intra-individuais constatadas entre as gônadas direita e esquerda, representadas conjuntamente pelo testículo e seu corpo ovariano associado, se apresentaram com nítidas assimetrias e com diferentes peculiaridades. As mais conspícuas variações interindividuais constatadas no aparelho reprodutor se apresentaram na forma, localização e vascularização superficial dos testículos. Também nos corpos adiposos e no ovário rudimentar ocorreram variações, porém menos acentuadas.

Quanto à forma, os testículos de C. ornatus são comumente órgãos cilíndricos que têm coloração branco-leitosa e possuem uma estrutura ovariana rudimentar, o órgão de Bidder, em sintopia com a extremidade testicular cranial. Na maioria dos indivíduos, a forma 
predominante da gônada foi de uma estrutura sólida cilindriforme, de diâmetro uniforme (Figuras 1 a 5). A variação mais evidente, observada em um indivíduo, foi o testículo dividido em dois lobos por uma fissura transversal. No outro, o testículo apresentou forma afilada na extremidade caudal (Figuras 3 e 5)

O comprimento médio (testículo + órgão de Bidder) da gônada direita é de $10,19 \pm 1,32 \mathrm{~mm}$ e o da esquerda é de 10,36 $\pm 1,47 \mathrm{~mm}$. Considerando ambos os testículos, excluindo as dimensões do órgão
(1)

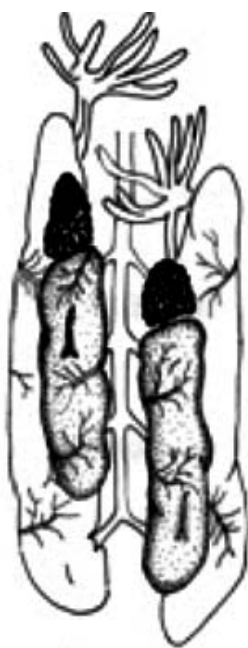

(2)

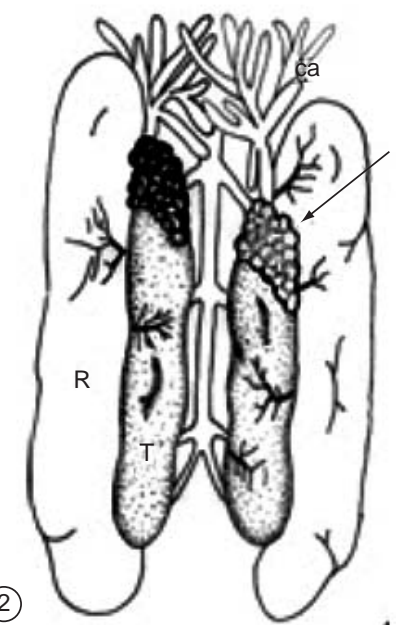

(3)

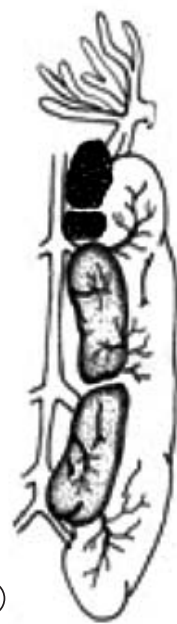

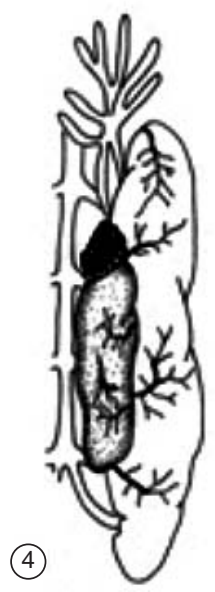

(5)

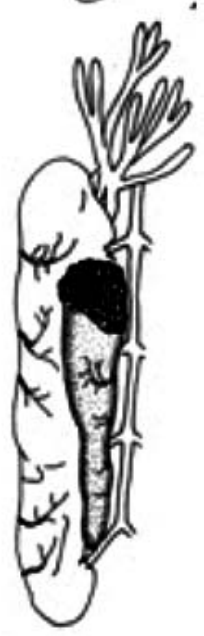

Figuras 1-5. Representação esquemática do aparelho urogenital masculino de Chaunus ornatus. Indicados: rim (R); testículo (T); órgão de Bidder (seta); e corpos adiposos abdominais (ca). Em 1) testículos dispostos em alturas diferentes e o órgão de Bidder separado do testículo homolateral por uma fissura; 2) o órgão de Bidder esquerdo está desprovido de pigmentação e o testículo direito apresenta discreta vascularização superficial; 3) testículo esquerdo e o órgão de Bidder homolateral estão divididos por fissuras conspícuas; 4) rim, testículo e o órgão de Bidder esquerdos relativamente menores que nos demais exemplares; e 5) testículo direito com forma afilada na extremidade posterior.

Figures 1-5. Schematic representation of the male urogenital system of Chaunus ornatus. Indication: kidney (R); testis (T); Bidder's organ (arrow); and abdominal fatty bodies (ca). In 1) testes disposed in different levels and the Bidder's organ separate from the homolateral testis by a fissure; 2) the left Bidder's organ is without pigmentation and the right testis presents discreet superficial vascularization; 3) left testis and the homolateral Bidder's organ are divided by conspicuous fissures; 4) kidney, left testis and Bidder's organ relatively smaller than the other units; and 5) right testis with thin form in the posterior extremity. de Bidder, apresentaram o comprimento médio de $8,1 \pm 1,1 \mathrm{~mm}$. Pelos testes não há diferença estatística entre os pares e quando ocorreu a assimetria de tamanho, esta foi pequena. O comprimento médio do testículo direito é de $8,15 \pm 1,16 \mathrm{~mm}$ e do esquerdo é de $8,05 \pm$ $1,06 \mathrm{~mm}$. As medidas dos diâmetros demonstraram ser uniformes, a média do direito foi $1,56 \pm 0,37 \mathrm{~mm}$ e a do esquerdo $1,79 \pm 0,27 \mathrm{~mm}$. As variações no tamanho podem ocorrer, e possivelmente devem estar relacionadas ao desenvolvimento gonadal na época da reprodução ou com outros fatores, mas não estão necessária e diretamente associadas ao biótipo do animal.

As informações anatômicas também são importantes para compreensão da biologia reprodutiva de algumas espécies, como no gênero Leptodactylus. O maior tamanho relativo dos testículos nas espécies Leptodactylus chaquensis $(4,13 \%)$ e L. podicipinus $(0,75 \%)$ está associado com a competição de esperma. Esse tipo de reprodução, na qual a desova recebe esperma de vários indivíduos também ocorre em outras espécies da família Rhacophoridae (Prado \& Haddad 2003).

Quanto à localização os testículos dispõem-se ventralmente aos rins, mas ocorrem em alturas diferentes, acompanhando diferenças atribuídas à própria posição dos primeiros (Figuras 1 e 2). O comprimento médio do rim direito é de $15,86 \pm 1,08 \mathrm{~mm}$ e o do esquerdo é de 14,71 \pm 0,47 mm. Assim, a disposição de um dos testículos preferencialmente em altura diferente é porque o rim homolateral também se dispõe em altura diferente nessa mesma localização. Com isso, pode-se inferir uma provável relação com o desenvolvimento embrionário e larval dos órgãos que constituíram o esboço urogenital, permanecendo no adulto com essas características. Além disso, estes sistemas se acomodam aos órgãos vizinhos de modo a não interferir nos seus estados funcionais, mantendo portando relativa mobilidade na cavidade corporal. Em Scinax fuscovarius as assimetrias morfológicas de tamanho, forma e localização, além de caracterizarem peculiaridades da espécie também podem ser atribuídas a aspectos funcionais. Quando deslocadas para diferentes alturas, profundidades e disposições garantem boa mobilidade em relação às vísceras adjacentes, não afetando os estados fisiológicos destes órgãos (Oliveira \& Vicentini 1998).

Normalmente os testículos são mais lisos, firmes e menores que os ovários na mesma espécie e, entre os membros do par, é comum a ocorrência de assimetrias de tamanho e posição (Hildebrand 1995), observados em outras espécies como Scinax fuscovarius (Oliveira \& Vicentini 1998) e Rana esculenta (Kükenthal et al. 1986). Nos anuros, de forma geral, o corpo é muito deprimido e os testículos são compactos e não estão divididos em lobos (Lofts 1974, Duellman \& Trueb 1994, Hildebrand 1995). São estruturas esféricas ou ovais podendo em algumas espécies serem longos e se estenderem até a extremidade posterior dos rins (Duellman \& Trueb 1994). Nos testículos de Caudiverbera caudiverbera pode-se diferenciar três regiões: cranial, medial e caudal (Hermosilla et al. 1983).

Quanto à vascularização superficial, uma observação angioarquitetural na distribuição dos vasos sanguíneos da túnica albugínea permite constatar que há evidentes diferenças na disposição entre os pares (Figuras 1 e 2). Os vasos sangüíneos arteriais que transitam pela cápsula testicular, após curto trajeto, penetram o órgão e estabelecem a vascularização do tecido inter-locular e do parênquima (Figura 6). O retorno venoso se dá por vasos que têm trajetória análoga, mas de fluxo em sentido oposto. Mesmo sem o propósito de estabelecer o mapeamento dos vasos arteriais ou venosos, constata-se que há evidentes diferenças angioarquiteturais na distribuição dos vasos sanguíneos da túnica albugínea também entre os indivíduos, como identificado entre os pares gonadais (Figuras 1 a 5).

A característica anatômica da família Bufonidae que representa uma exclusividade do táxon, o órgão de Bidder, que ocorre 
em macho e em fêmeas (Witschi 1933, Pancak-Roessler et al. 1990), é uma estrutura vestigial não-funcional nos machos ou uma extensão do ovário nas fêmeas e para o grupo representa uma condição derivada nos anuros, mas uma condição primitiva para a família (Pancak-Roessler et al. 1990). Nos órgãos de Bidder de Chaunus ornatus comumente há uma coloração discretamente parda, que está relacionada aos próprios ovócitos, sempre identificados na categoria não-vitelogênicos, associados aos quais está uma pigmentação que confere a cor típica. Pigmentação associada ao órgão e presença de ovócitos pré-vitelogênicos também são relatados para Anaxyrus woodhousii (Pancak-Roessler et al. 1990) e Nectophrynoides malcolmi (Wake 1980). Uma variação intra-individual ocorreu em um indivíduo, no qual um dos pares do órgão é totalmente desprovido de pigmentos enquanto o outro membro do par se apresentou como nos demais indivíduos, pigmentado (Figura 2). Esse órgão está intimamente associado à extremidade cranial do testículo juntamente com alguns prolongamentos dos corpos adiposos. De modo geral o órgão está acoplado à extremidade cranial gonadal, mas em dois exemplares uma fissura separando-os foi identificada (Figuras 1 e 3). O indivíduo que apresentou o testículo segmentado em lobos testiculares teve

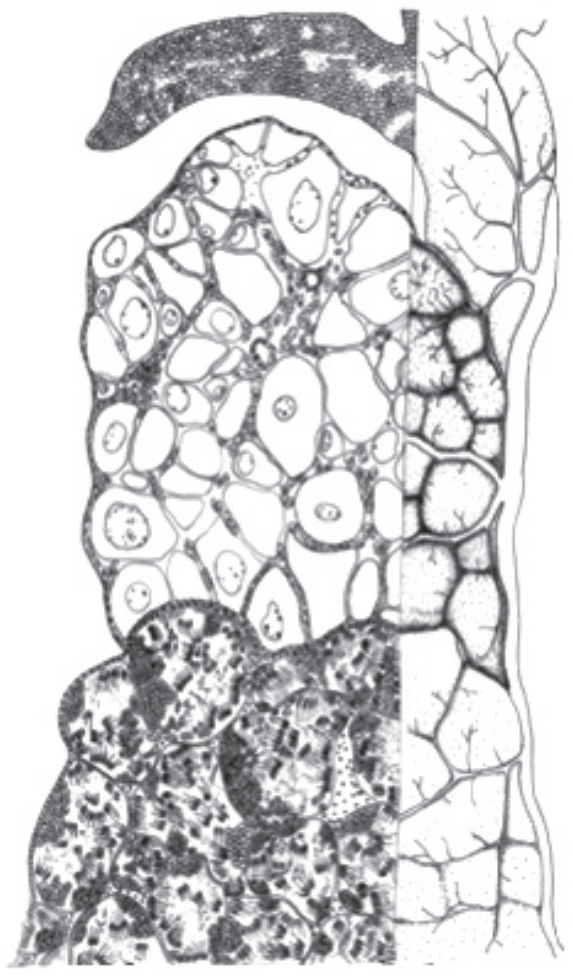

Figura 6. Detalhe do aspecto anatômico, em Chaunus ornatus, do órgão de Bidder acoplado ao pólo testicular e em íntima associação com um prolongamento dos corpos adiposos abdominais. À direita do esquema a representação é do aspecto histológico e a esquerda está o aspecto anatômico, com destaque para a conspícua vascularização das três estruturas constituintes do aparelho. As unidades representadas no órgão de Bidder são ovócitos não-vitelogênicos e no testículo são os lóculos seminíferos.

Figure 6. Details of the anatomical aspect, in Chaunus ornatus, of the Bidder's organ coupled to the testicular pole and in close association with a extension of the abdominal fatty bodies. At the right region of the illustration is represented the histological aspect and at the left the anatomical aspect, highlighting the conspicuous vascularizations of the three structures of the system. The units represented in the Bidder's organ are oocytes non-vitellogenics and in the testis are seminiferous locules. uma segmentação similar no tecido ovariano que também o dividiu em dois lobos independentes, desiguais no tamanho, e ambos totalmente separados do testículo homolateral com o qual naturalmente estabelece sintopia (Figura 3). Quantificado o tamanho desse órgão, o comprimento médio do esquerdo é 2,31 $\pm 0,48 \mathrm{~mm}$ e do direito é $2,04 \pm 0,48 \mathrm{~mm}$ e, pelos testes, o seu tamanho se mostrou independente do tamanho do testículo correspondente (Figuras 6 e 7).

De acordo com Witschi (1933) estes órgãos manifestam grande variabilidade, tanto na forma quanto no tamanho, mas comumente varia de $1 / 2$ a $1 / 4$ do tamanho do testículo, podendo em espécies como Bufo bufo ser até maior que o próprio testículo. Em C. icterictus (Farias et al. 2002) há uma característica região medular e uma região cortical onde estão dispostos os folículos Bidderianos. Em C. ornatus não foi observada uma distinção entre estas duas regiões de modo tão conspícuo. Para Nectophrynoides malcolmi (Wake 1980) a forma é ainda mais peculiar, diferindo do padrão comumente descrito para os integrantes da família Bufonidae, sendo uma faixa de tecido ovariano que se estende lateralmente de um pólo ao outro do testículo, perifericamente.

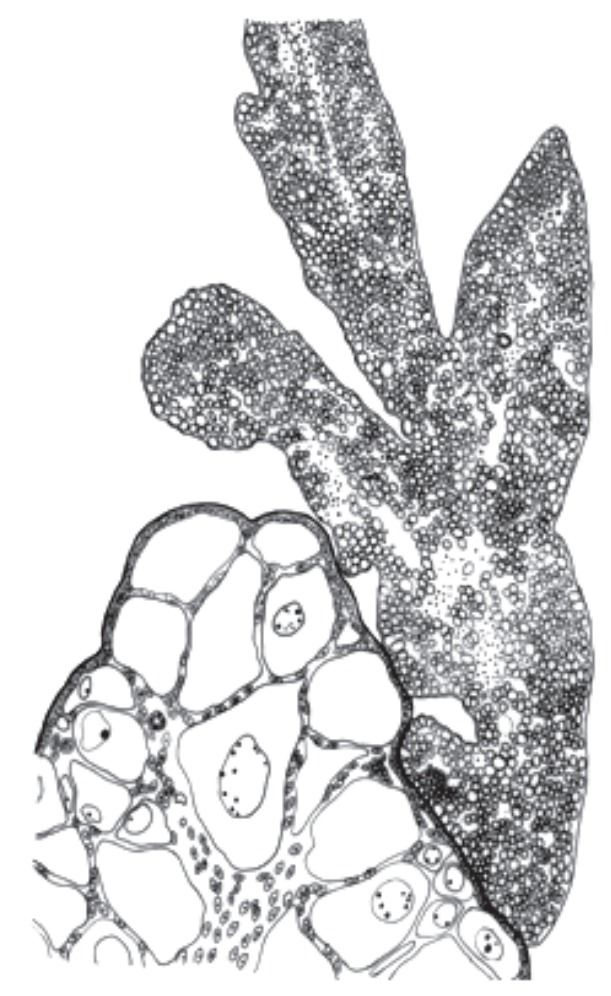

Figura 7. Corpo adiposo em sintopia com a superfície do órgão de Bidder, em Chaunus ornatus. Os espaços vacuolizados são células adiposas imersas no escasso tecido conjuntivo. Uma delgada camada externa que envolve o testículo é contínua com a camada que reveste o órgão de Bidder, na qual também podem se fixar prolongamentos dos corpos adiposos. Pode-se observar no parênquima Bidderiano uma discreta região medular com várias células intersticiais e diversas células germinativas, que incluem as ovogônias e ovócitos não-vitelogênicos.

Figure 7. Fatty body in close association with the surface of the Bidder's organ in Chaunus ornatus. The vacuoles are fatty cells immersed in the scarce conjunctive tissue. A thin external layer involves the testis and is continuous with the layer that covers the Bidder's organ, in which fatty bodies prolongations can also be fixed. In the Bidderian parenchyma a discrete medular area with several interstitial cells and several germ cells can be observed, that includes the oogonia and oocytes non-vitellogenic. 
Nos corpos adiposos abdominais, a disposição e número de prolongamento que o constitui é variável entre os membros do par, e conseqüentemente entre indivíduos (Figuras 1 a 5). Porém, o volume aparente que essa estrutura mantém desse tecido adiposo entre os dois antímeros não diverge muito no aspecto macroscópico, no entanto, os corpos adiposos abdominais podem estar muito reduzidos ou extraordinariamente desenvolvidos, refletindo uma alteração anatômica que varia de acordo com o estado funcional de acúmulo lipídico no tecido adiposo multilocular que o constitui. Estas estruturas naturalmente se apresentam de cor amarela intensa, hialina ou relativamente opaca, e a vascularização ocorre por meio de vasos mais calibrosos que transitam longitudinalmente aos prolongamentos digitiformes (Figura 6). Uma característica anatômica nessa espécie e que parece relevante, talvez outra característica da família Bufonidae diferenciando estas espécies de outras famílias de anuros, é atribuído aos corpos adiposos estarem intimamente aderidos ao mesórquio dos rins (Figuras 1 a 5) em comparação à adesão comumente descrita para maioria dos anuros junto ao pólo cranial das gônadas. No entanto, na maioria dos exemplares alguns prolongamentos dos corpos adiposos se estendem até órgão de Bidder (Figuras 6 e 7). Variações dos corpos adiposos foram constatadas em algumas espécies de anfíbios (Fitzpatrick 1976, Lampo \& Medialdea 1996). Quanto à forma, nos Caudata são fitas longitudinais localizadas paralelamente entre as gônadas e rins, e nos Gymnophiona estão organizados em numerosos corpos em forma de folhas (Duellman \& Trueb 1994).

As características anatômicas do arranjo histológico testicular (Figuras 6 e 7) é relativamente simples e parece seguir o padrão da descrição para os demais anuros (Oliveira \& Vicentini 1998, Oliveira et al. 2002, Oliveira et al. 2003a, Oliveira \& Zieri 2005). Revestindo o testículo encontra-se uma fina cápsula de tecido conjuntivo constituída de uma camada celular simples pavimentosa, a túnica albugínea, por transparência da qual se observa a coloração típica do parênquima testicular, de cor branco-leitoso. Externamente são facilmente distinguidos os lóculos seminíferos, estes por sua vez, são entremeados e delimitados pelo tecido inter-locular representado por estruturas que constitui o tecido de suporte anatômico às estruturas seminíferas, fibras da matriz e fibroblastos, e células de natureza aparentemente secretora (Figura 6). Além destas, transitam pelo interstício uma variedade de estruturas, dentre as quais, os nervos, vasos sanguíneos e alguns dúctulos eferentes.

Em relação a outros anuros pode-se constatar que certos aspectos anatômicos são característicos, às vezes exclusivos a um grupo de animais, como para o Leptodactylidae Eupemphix nattereri (Oliveira \& Zieri 2005), cujo tecido inter-locular embora seja muito similar quanto às estruturas constituintes, nestas espécies há uma intensa pigmentação, que também ocorre na túnica albugínea, conferindo aos testículos colorações variando do preto intenso ao preto mesclado com branco. Em outras espécies a pigmentação testicular também é descrita em Physalaemus fuscomaculatus (Aoki et al. 1969), Bombina bombina (Gollmann et al. 1993), Xenopus laevis (Zuasti et al. 1998) e Physalaemus cuvieri (Oliveira et al. 2002, 2003a). A presença de células com grande quantidade de inclusões pigmentares associadas aos órgãos do aparelho reprodutor também ocorre com várias outras vísceras e estruturas, pigmentação visceral que pode ser verificada a olho desarmado e que constitui o sistema pigmentar extracutâneo (Oliveira \& Zieri 2005). Nos testículos de Chaunus ornatus não foram detectadas células manifestando pigmentação gonadal, mas os órgãos de Bidder apresentam uma típica coloração própria que possibilita uma fácil distinção entre o testículo e esse órgão ovariano remanescente.

Delimitados por este tecido conjuntivo frouxo, os lóculos constituem unidades morfológicas, ou seja, os elementos seminíferos das gônadas, para as quais não foram observadas qualquer característica de regionalização do parênquima ou do estroma testicular, dessa forma os lóculos seminíferos e o tecido inter-locular se distribuem uniformemente. Histologicamente também não foram observadas diferenças quanto ao arranjo do epitélio germinativo na constituição do lóculo seminífero. Desse modo nenhuma diferença histológica quanto ao arranjo dos testículos foi notificada (Figura 6).

Em vertebrados, como os mamíferos, septos emitidos junto à túnica albugínea delimitam pronunciadas lobulações incompletas que abrigam os túbulos seminíferos (Hildebrand 1995). Nos anuros, os testículos não apresentam lobos nem lóbulos como ocorre anatomicamente em muitos urodelos e nos ápodes (Duellman \& Trueb 1994). Porém em C. ornatus, os testículos podem apresentar lobações, como constatado em um exemplar, mas não possuem septações do parênquima testicular. Assim, alguns indivíduos apresentam uma variação do padrão anatômico mais comum da espécie, isto é, apresentam os testículos divididos por fissuras completas em unidades que identificadas como lobos testiculares à semelhança das lobações comumente caracterizadas nas outras ordens de anfíbios. Histologicamente o parênquima testicular não apresenta o aspecto tubular típico similar ao dos mamíferos uma vez que e as unidades seminíferas são denominadas de lóculos seminíferos. Estas características do parênquima e arranjo do tecido germinativo são comumente descritas em espécies de distintas famílias de anuros (Oliveira \& Vicentini 1998, Oliveira et al. 2003a, Oliveira \& Zieri 2005).

Quanto ao epitélio germinativo, possuem agrupamentos celulares (espermatocistos ou cistos espermatogenéticos) de células da linhagem espermatogenética com as células somáticas de Sertoli. Esse arranjo é uma característica comum para os anfíbios (Duellman \& Trueb 1994, Oliveira et al. 2002, 2003b), mas não exclusiva, pois ocorre em outros anamniotas (Grier 1992). As células germinativas estão intimamente associadas às células de Sertoli formando espermatocistos de espermatogônias, espermatócitos e espermátides, que ao final da citodiferenciação se organizam em feixes de espermatozóides (Figura 6). No epitélio germinativo a distribuição dos cistos aparentemente não segue uma ordem de distribuição, identificando-se apenas as espermatogônias próximas à parede do lóculo e os feixes de espermatozóides, geralmente, próximos ou no lume locular. Descrição também reportada para A. woodhousii (Atherton 1974) que se refere a uma disposição aleatória. Nos testículos de Caudiverbera caudiverbera foram diferenciadas regiões (cranial, medial e caudal), porém, não existem diferenças quanto ao arranjo dos elementos seminíferos nas mesmas (Hermosilla et al. 1983).

Relatam-se descrições do epitélio germinativo, de modos similares para a maioria das espécies de diferentes famílias e em especial também para outras espécies integrantes da família Bufonidae - Chaunus arenarum (Cavicchia \& Moviglia 1982), Duttaphrynus melanostictus (Huang et al. 1997), Amietophrynus regularis (Abdelmaguid \& Sabry 1987), Anaxyrus. woodhousii (Atherton 1974), Nectophrynoides occidentalis (Zuber-Vogeli \& Xavier 1966) e genus Telmatobius (Montero \& Pisanó 1990). Os aspectos gerais da espermatogênese mantêm o padrão das descrições em espécies de outros táxons: Hylidae - Pachymedusa dacnicolor (Rastogi et al. 1988); Scinax ranki (Taboga \& Dolder 1991); Hyla japonica (Lee \& Kwon 1992); Hypsiboas pulchella andina (Montero \& Pisanó 1992) e Scinax fuscovarius (Oliveira \& Vicentini 1998, Oliveira et al. 2003b); Leptodactylidae - Physalaemus fuscomaculatus (Aoki et al. 1969); Caudiverbera caudiverbera (Hermosilla et al. 1983); Bombina bombina (Gollmann et al. 1993); Physalaemus cuvieri (Oliveira et al. 2002, 2003a) e Eupemphix nattereri (Oliveira \& Zieri 2005)

A heterogeneidade morfológica relativamente grande nessa espécie quanto às variações anatômicas parece uma constatação pouco 
significativa, mas estas diferenças em poucos indivíduos podem estar relacionadas com muitos aspectos. Assim, outros estudos ainda são necessários para o estabelecimento de relações morfológicas e suas implicações filogenéticas, bem como para compreender como as pressões evolutivas atuam moldando a anatomia dessas estruturas nos anuros.

\section{Agradecimentos}

Ao Biólogo Denílson F. Peralta pela elaboração das figuras esquemáticas. A FAPESP pelo auxílio à pesquisa - processo n. 02/08016-9. A CAPES pela concessão das bolsas de Mestrado para Rodrigo Zieri e para Lia Raquel de Souza Santos.

\section{Referências Bibliográficas}

ABDELMAGUID, N. \& SABRY, I. 1987. Cyclic spermatogenesis in the testis of the Egyptian toad (Bufo regularis). Folia Morphol. 35(4):381-386.

AOKI, A., VITALE-CALPE, R., PISANO, A. 1969. The testicular interstitial tissue of the amphibian Physalaemus fuscomaculatus. Z. Zellforsch. Mikrosk. Anat. 98:9-16.

ATHERTON, R.W. 1974. A gradient analysis of spermatogenesis in the toad Bufo woodhousei Girard (1854). Herpetologica. 30:240-244.

CAVICCHIA, J.C. \& MOVIGLIA, G.A. 1982. Fine structure of the testis in the toad (Bufo arenarum Hensel): a freeze-fracture study. Anat. Rec. 203(4):463-474.

DUELLMAN, W.E. \& TRUEB, L. 1994. Biology of amphibians. New York, McGraw-Hill, p.670.

FARIAS, C.F., CARVALHO-SILVA, S.P., BRITO-GITIRANA, L. 2002. Bidder's organs of Bufo ictericus: a light and electron microscopy analysis. Micron. 33:673-679.

FITZPATRICK, L.C. 1976. Life history patterns of storage and utilization of lipids for energy in amphibians. Am. Zool. 16:725-732.

GOLLMANN, G., BORKIN, L.J., ROTH, P. 1993. Genic and morphological variation in the fire-bellied toad, Bombina bombina (Anura, Discoglossidae). Zool. Jahrb. Abt. Syst. Oekol. Geogr. Tiere. 120:129-136.

GRIER, H.J. 1992. Chordate tetis: the extracellular matrix hypothesis. J. Exp. Zool. 261(2):151-160.

HERMOSILLA, I.B., URBINA, A.P., CABRERA, J.C.P. 1983. Espermatogenesis en la rana Chilena Caudiverbera caudiverbera (Linne, 1758) (Anura, Leptodactylidae). Bol. Soc. Biol. Concepción. 54:103-115.

HILDEBRAND, M. 1995. Análise da estrutura dos vertebrados. Atheneu, São Paulo, p.700.

HUANG, W.S., LIN, J.Y., YU, J.Y.L. 1997. Male reproductive cycle of the toad Bufo melanostictus in Taiwan. Zool. Sci. 14(3):497-503.

KÜKENTHAL, W., MATTHES, E., RENNER, M. 1986. Amphibia. In Guia de Trabalhos Práticos de Zoologia. 15 a ed. Coimbra, Atlântida, p.368-389.

LAMPO, M. \& MEDIALDEA, V. 1996. Energy allocation patterns in Bufo marinus from two habitats in Venezuela. J. Trop. Ecol. 12(3):321-331.

LEE, M.S.Y., KWON, A.S. 1992. Ultrastructure of spermiogenesis in Hyla japonica (Anura, Amphibia). Acta Zool. 73:49-55.

LOFTS, B. 1974. Reproduction. In Physiology of the amphibians (B. LOFTS, ed) Academic Press, New York, v.2, p.107-218.

MONTERO, R. \& PISANÓ, A. 1990. Ciclo espermatogénico de dos especies de Telmatobius del noroeste argentino. Amphib-Reptilia. 11:97-110.

MONTERO, R. \& PISANÓ, A. 1992. El ciclo espermatogénico anual de Hyla pulchella andina: un análisis numérico. Acta Zool. Lilloana. 41:173-180.

OLIVEIRA, C. \& VICENTINI, C.A. 1998. Descrição anatômica dos testículos e corpos adiposos de Scinax fuscovarius (Anura, Hylidae). Biociências. 6(1):79-88.
OLIVEIRA, C., ZANETONI, C., ZIERI, R. 2002. Morphological observations on the testes of Physalaemus cuvieri (Amphibia, Anura). Rev. Chil. Anat. 20(3):263-268.

OLIVEIRA, C., SANTANNA, A.C., OMENA, P.M., SANTOS, L.R.S., ZIERI, R. 2003a. Morphological considerations on the seminiferous structures and testes of anuran amphibians: Bufo crucifer, Physalaemus cuvieri and Scinax fuscovarius. Biociências. 11(1):39-46.

OLIVEIRA, C., VICENTINI, C.A., TABOGA, S.R. 2003b. Structural characterization of nuclear phenotypes during Scinax fuscovarius spermatogenesis (Anura, Hylidae). Caryologia. 56(1):75-83.

OLIVEIRA, C. \& ZIERI, R. 2005. Pigmentação testicular em Physalaemus nattereri (Steindachner) (Amphibia, Anura) com observações anatômicas sobre o sistema pigmentar extracutâneo. Rev. Bras. Zool. 22(2):454-460.

PANCAK-ROESSLER, M.K., SMITH, H.M., CHISZAR, D. 1990. Bidder's organs: Bufonid by-products of the evolutionary loss of hyperfecundity. Amphib-Reptilia. 11:225-235.

PRADO, C.P. \& HADDAD, C.F.B. 2003. Testes size in leptodactylid frogs and occurrence of multimale spawning in the genus Leptodactylus in Brazil. J. Herpetol. 37(2):354-362.

RASTOGI, R.K., BAGNARA, J.T., IELA, L., KRASOVICH, M.A. 1988. Reproduction in the mexican leaf frog, Pachymedusa dacnicolor. IV.Spermatogenesis: a light amd ultrasonic study. J. Morph. 197(3):277302.

RIBEIRO, M.G. \& LIMA, S.R. 2000. Iniciação às técnicas de preparação de material para estudo e pesquisa em morfologia. Segrac Editora, Belo Horizonte, p.89.

TABOGA, S.R. \& DOLDER, M.A.H. 1991. Análise histológica da espermatogênese de Hyla ranki (Amphibia, Anura, Hylidae). Braz. J. Morphol. Sci. 8(2):66-71.

WAKE, M.H. 1980. The reproductive biology of Nectophrynoides malcolmi (Amphibia: Bufonidae), with comments on the evolution of reproductive modes in the genus Nectophrynoides. Copeia. 2:193-209.

WITSCHI, E. 1933. Studies in sex differentiation and sex determination in amphibians. VI. The nature of Bidder's organs in the toad. Amer. J. Anat. 52:461-515.

ZUASTI, A., JIMÉNEZ-CERVANTES, C., GARCÍA-BORRÓN, J.C., FERRER, C. 1998. The melanogenic system of Xenopus laevis. Arch. Histol. Cytol. 61(4):305-316.

ZUBER-VOGELI, M. \& XAVIER, F. 1966. La spermatogénèse de Nectophrynoides occidentalis au cours du cycle annuel. Bull. Soc. Zool. Fr. 90:261-267.

Título: Variações anatômicas no aparelho reprodutor masculino de Chaunus ornatus (Wied-Neuwied, 1821) (Anura, Bufonidae).

Autores: Oliveira C, Santos, LRS e Zieri, R

Biota Neotropica, Vol.7 (número 1): 2007

http://www.biotaneotropica.org.br/v7n1/pt/abstract?article+bn 01207012007

Recebido em 13/07/06 - Versão reformulada recebida em 10/12/06 - Publicado em 10/01/07

ISSN 1676-0603 